\title{
IMPACTO DE LA PANDEMIA EN LA SALUD MATERNA EN EL PERÚ
}

\author{
IMPACT OF THE PANDEMIC ON MATERNAL HEALTH IN PERU
}

\author{
Enrique Guevara Ríos ${ }^{1,2, a}$
}

Según el Centro Nacional de Epidemiología, Prevención y Control de Enfermedades del Ministerio de Salud, en el 2018 la primera causa de muerte materna en el Perú fueron los trastornos hipertensivos del embarazo, con un $22 \%$ de todas las causas, seguido de las hemorragias obstétricas con el $18,9 \%{ }^{1}$.

Fue la primera vez que en el Perú los trastornos hipertensivos del embarazo superaron a las hemorragias del embarazo, que es la primera causa de muerte materna en el mundo con cerca de un $27 \%{ }^{2}$.

En el 2019, las hemorragias del embarazo nuevamente ocuparon el primer lugar como causa de muerte materna con el $26 \%$, seguido muy de cerca por los trastornos hipertensivos con un $19,6 \%{ }^{3}$.

En el 2020, los trastornos hipertensivos del embarazo ocuparon el primer lugar como causa de muerte materna con el $21,4 \%$ seguido de las hemorragias del embarazo con el $18 \%{ }^{3}$.

De alguna manera en el Perú se está manejando adecuadamente la prevención de las hemorragias del embarazo especialmente las hemorragias post parto, utilizando las estrategias recomendadas por la OMS, quien recomienda el manejo activo de la tercera etapa del parto con la administración de oxitocina antes que transcurra un minuto después del nacimiento del bebé, asociado a la tracción controlada del cordón umbilical y al masaje uterino después del nacimiento de la placenta cuando corresponda ${ }^{4}$, así como el uso de la clave roja en todos los establecimientos de salud ${ }^{5}$.

Lamentablemente en el 2020, desde el mes de marzo, en que se diagnosticó el primer caso de infección por COVID-19, las gestantes se han vuelto una población vulnerable que ha producido graves consecuencias en su salud, lo cual se ve representado por el incremento de muertes maternas en el 2020 a 439 casos, y es además la tercera causa de muerte materna después de los trastornos hipertensivos y de las hemorragias del embarazo, con un $15,3 \%^{3}$.

Esta situación implica mejorar la atención prenatal con consultas virtuales, a través de la telemedicina y consultas presenciales, así como promover el parto institucional con todas las medidas de bioseguridad que se vienen dando en todos los hospitales del país, ya sea se trate de un parto vaginal o de una cesárea electiva; y también, es importante considerar a las gestantes como una población vulnerable que requiere una pronta vacunación contra la COVID-19.

En el Instituto Nacional Materno Perinatal desde el mes de abril del 2020, se inició la atención prenatal de las gestantes a través de la teleconsulta y desde noviembre se viene brindando una atención prenatal mixta: virtual y presencial. Además, recientemente gracias a una investigación operativa que vienen realizando en el Departamento de Obstetricia y Perinatología, destacados médicos gineco-obstetras, con el apoyo de CONCYTEC, han desarrollado un aplicativo móvil que permite realizar atención y seguimiento a las gestantes a través de un acceso al esquema de atención prenatal, así como información importante sobre el embarazo.

1 Instituto Nacional Materno Perinatal. Lima, Perú.

2 Departamento de Ginecología y Obstetricia. Universidad Nacional Mayor de San Marcos. Lima, Perú.

a Médico Ginecólogo-Obstetra. Director del Instituto Nacional Materno Perinatal. Profesor Ordinario de la Facultad de Medicina, Universidad Nacional Mayor de San Marcos Lima-Perú. Coordinador de Asistencia Técnica del Instituto de Salud Popular.

(D) Código ORCID: https://orcid.org/0000-0002-6962-2639, Enrique Guevara Rios

Citar como: Guevara Ríos E. Impacto de la pandemia en la salud materna en el Perú. Rev Peru Investig Matern Perinat 2021; 10(1): 7-8 DOI https://doi.org/10.33421/inmp.2021230

Recibido: 22-02-2021 Aprobado: 31-03-2021 
Esperamos que estas experiencias se puedan replicar en todos los establecimientos de salud, con el único de objetivo de garantizar una buena calidad de atención a las gestantes y que al finalizar su embarazo puedan ellas y sus recién nacidos estar en las mejores condiciones de salud, y además podamos todos contribuir a la disminución de la muerte materna en el Perú.

Financiamiento: Autofinanciado.

Conflicto de interés: El autor declara no tener algún conflicto de interés.

\section{REFERENCIAS BIBLIOGRÁFICAS}

1. Ministerio de Salud Centro Nacional de Epidemiología, Prevención y Control de Enfermedades. *Hasta SE 52 - 2018/ Cierre de base preliminar base 2018 . Se consideraron todas las muertes notificadas. Datos disponibles de investigación epidemiológica actualizados al 13/01/2019.
2. Say L, Chou D, Gemmill A, Tunçalp Ö, Moller A, Daniels J, et al. Global causes of maternal death: a WHO systematic análisis. Lancet Glob Health. 2014 Jun; 2(6): e323-33. DOI: 10.1016/S2214-109X (14)70227-X).

3. Ministerio de Salud. Centro Nacional de Epidemiología, Prevención y Control de Enfermedades del 2021: Hasta la SE 03.

4. Organización Mundial de la Salud. Recomendaciones de la OMS para la prevención y el tratamiento de la hemorragia posparto. ISBN 978924354850 0. 2014.

5. Ministerio de Salud. Dirección General de Salud de las Personas. Estrategia Sanitaria Nacional de Salud Sexual y Reproductiva Manejo Estandarizado de las Emergencias Obstétricas y Neonatales: Módulo 1. Modelo de intervención para mejorar la Disponibilidad, Calidad y Uso de los Establecimientos que cumplen Funciones Obstétricas y Neonatales. Lima. 2010. 